\title{
Trace Elemental Analysis of Commercial Bottled Drinking Water by a Portable Total Reflection X-ray Fluorescence Spectrometer
}

\author{
Shinsuke KUnIMURA ${ }^{\dagger}$ and Jun KawaI \\ Department of Materials Science and Engineering, Kyoto University, Sakyo, Kyoto 606-8501, Japan
}

\begin{abstract}
A portable total reflection X-ray fluorescence spectrometer was applied to commercial bottled drinking water containing $62 \mathrm{ppb}(\mu \mathrm{g} / \mathrm{L}) \mathrm{V}, 7.5 \mathrm{ppm}(\mathrm{mg} / \mathrm{L}) \mathrm{Ca}$, and $1 \mathrm{ppm} \mathrm{K}$. A dry residue, prepared by repeated pipetting and drying a $20 \mu \mathrm{L}$ portion of drinking water on a sample holder six times, and another dry residue, prepared by pipetting and drying a 120 $\mu \mathrm{L}$ portion of the drinking water, were measured. The size of the dry residue of the drinking water was reduced by repeating the pipetting and drying. Calcium and potassium were easily detected in these two dry residues. Vanadium was detected in the dry residue prepared by repeated pipetting and drying. Vanadium, calcium, and potassium were quantified by using an internal standard, and the average quantified concentrations of $\mathrm{V}, \mathrm{Ca}$, and $\mathrm{K}$ were $91 \mathrm{ppb}, 8.2 \mathrm{ppm}$, and $1.5 \mathrm{ppm}$, respectively. Although these quantified concentrations deviated from the certified concentrations (62 ppb of $\mathrm{V}, 7.5 \mathrm{ppm}$ of $\mathrm{Ca}$, and $1 \mathrm{ppm}$ of $\mathrm{K}$ ), it was possible for this portable spectrometer to estimate approximate concentrations.
\end{abstract}

(Received May 15, 2007; Accepted August 7, 2007; Published October 10, 2007)

The total reflection X-ray fluorescence (TXRF) analysis, ${ }^{1,2}$ which was first proposed by Yoneda and Horiuchi, ${ }^{3}$ was used for environmental analysis as follows. TXRF analysis was applied to rain water, ${ }^{4}$ atmospheric aerosols in a city, ${ }^{5}$ river water, ${ }^{6}$ soils, ${ }^{7}$ seawater, ${ }^{8}$ and biofilms. ${ }^{9}$ It has been possible for TXRF analysis to perform simultaneous multi-elemental determinations, measurements in air, and measurements of microliters of samples. Using a high-power X-ray source has reduced the detection limit for elements. Wobrauschek et al. ${ }^{10}$ reported that using a monochromatized synchrotron radiation for TXRF analysis achieved femtogram detection limit. TXRF spectrometers with a high-power X-ray tube, such as a rotating anode X-ray tube, have also detected low amounts of elements. These TXRF spectrometers have been stationary because the high-power X-ray tube has required water (several L/min) for cooling an anode, and have been operated with a few $\mathrm{kW}$ to a few tens of $\mathrm{kW}$ of power. In contrast to high-power X-ray tubes, air-cooled low-power X-ray tubes have not required cooling water, and have been operated with a few watts to tens of watts of power. These spectrometers have enabled to perform on-site analysis. Waldschläger ${ }^{11}$ reported on a portable TXRF spectrometer with a $40 \mathrm{~W}$ X-ray tube, and its application to environmental samples. Mages et al. ${ }^{12}$ reported that on-site analysis of environmental samples was performed by a portable TXRF spectrometer, which evolved from the spectrometer reported by Waldschläger. ${ }^{11}$ Yamada et al. ${ }^{13}$ reported on a portable TXRF spectrometer with a $50 \mathrm{~W}$ X-ray tube, and its application to near-surface analysis of flat glasses manufactured by float glass process. Kunimura and Kawai ${ }^{14}$ have designed, constructed and reported a portable TXRF spectrometer with a $1.5 \mathrm{~W}$ X-ray tube. This portable spectrometer consisted of the low-power X-ray tube, a waveguide-type slit, and a Si PIN photodiode detector. These components were contained in a

$\doteqdot$ To whom correspondence should be addressed.

E-mail: kunimur@0715.mbox.media.kyoto-u.ac.jp housing made from $\mathrm{Pb}$-containing acrylic slabs (equivalent to a $0.3 \mathrm{~mm}$ thick $\mathrm{Pb}$ plate). The size of this housing was $23 \mathrm{~cm}$ in height, $30 \mathrm{~cm}$ in width, and $9 \mathrm{~cm}$ in depth. This portable spectrometer was $5 \mathrm{~kg}$, but most of this weight was due to the housing. Although the continuum X-rays emitted from the lowpower X-ray tube were used for the excitation of fluorescent $\mathrm{X}$ rays, $1 \mathrm{ng}$ detection limit for $\mathrm{Cr}$ was achieved. This portable spectrometer was applied to leaching test solution of soils, and ppm concentrations or nanograms of $\mathrm{S}$ and $\mathrm{Ca}$ were detected. ${ }^{15}$ In the present report, this portable spectrometer was applied to commercial bottled drinking water containing $62 \mathrm{ppb}$ of vanadium.

\section{Experimental}

\section{Instrument}

Details of this portable spectrometer were reported in a previous paper, ${ }^{14}$ and are briefly summarized here. An X-ray tube, "N6601" (Hamamatsu Photonics Co., Hamamatsu, Japan), was used in the portable spectrometer. It was operated at 9.5 $\mathrm{kV}$ and $150 \mu \mathrm{A}$. The X-ray tube with a transmission-type anode material, tungsten, emitted continuum $\mathrm{X}$-rays because the maximum X-ray energy emitted from the X-ray tube was 9.5 $\mathrm{keV}$, whereas the $\mathrm{W} \mathrm{L}_{1}, \mathrm{~L}_{2}$, and $\mathrm{L}_{3}$ absorption edge energies were $12.1,11.5,10.2 \mathrm{keV}$, which were more than $9.5 \mathrm{keV}$ X-ray energy. A waveguide-type slit, which consisted of two parallel Si wafers, was placed between the X-ray tube and a specimen in order to obtain a parallel X-ray beam; the waveguide-type slit restricted the $\mathrm{X}$-rays to be $50 \mu \mathrm{m}$ in height and $10 \mathrm{~mm}$ in width. Sánchez ${ }^{16}$ presented an X-ray focusing tool for TXRF analysis which also consisted of two parallel Si wafers, "plate beamguides". Ayala ${ }^{17}$ proposed a TXRF spectrometer with a planar X-ray waveguide. A quartz optical flat $(30 \mathrm{~mm}$ in diameter, and $10 \mathrm{~mm}$ in thickness) was used as a sample holder. Fluorescent $\mathrm{X}$-rays were excited by the parallel X-ray beam illuminating a 
specimen on the optical flat. Although X-ray fluorescence (XRF) spectra, which were reported in previous papers, ${ }^{14,15}$ were measured by a Si PIN photodiode detector, "X-123", (Amptek Inc., Bedford, MA) containing a preamplifier and a digital signal processor in the detector housing, XRF spectra were measured by a Si PIN photodiode detector, "XR-100CR", containing a preamplifier in the detector housing (Amptek) in the present report. Effective detection area of these two detector was $7 \mathrm{~mm}^{2}$. The signal from the detector was amplified by an amplifier, "PX2CR" (Amptek), and the amplified signal was taken into a personal computer through a multi-channel analyzer, "MCA8000A" (Amptek). The number of channels of the multichannel analyzer was 512, and 1 channel corresponded to an Xray energy of $27 \mathrm{eV}$. All measurements were performed in air at the glancing angle of $0.13^{\circ}$ of the incident X-ray beam with respect to a quartz optical flat. The area where the surface of the optical flat was illuminated by the incident $\mathrm{X}$-ray beams was about $20 \mathrm{~mm}$ in length, and $10 \mathrm{~mm}$ in width.

\section{Sample preparation}

Commercial bottled drinking water was measured. This bottle contained $500 \mathrm{~mL}$ of drinking water, and was made from polyethylene terephthalate (PET). The certified concentrations of $\mathrm{V}, \mathrm{Ca}$, and $\mathrm{K}$ were $62 \mathrm{ppb}(\mu \mathrm{g} / \mathrm{L}), 7.5 \mathrm{ppm}(\mathrm{mg} / \mathrm{L})$, and 1 $\mathrm{ppm}$, respectively. PET bottles for drinks are used only once, and are not recycled, in Japan. The sample was prepared by the following two methods:

1. A $20-\mu \mathrm{L}$ portion of drinking water was pipetted onto the optical flat, and then it was dried on a heating plate. The pipetting and drying were repeated five times. The size of the dry residue was about $7 \mathrm{~mm}$ in diameter.

2. A $120-\mu \mathrm{L}$ portion of the drinking water was pipetted onto the optical flat, and then dried on a heating plate. The size of the dry residue was about $17 \mathrm{~mm}$ in diameter.

These dry residues, which contained $7 \mathrm{ng}$ of $\mathrm{V}, 900 \mathrm{ng}$ of $\mathrm{Ca}$, and $120 \mathrm{ng}$ of $\mathrm{K}$, were measured for $500 \mathrm{~s}$.

Vanadium, calcium, and potassium in the drinking water were quantified by using an internal standard to compare the quantified concentrations with the certified concentrations, and $\mathrm{Mn}$ was used as the internal standard. A $20-\mu \mathrm{L}$ portion of mixed standard solution containing $1 \mathrm{ppm}$ of $\mathrm{Ca}, \mathrm{V}, \mathrm{Cr}$, and $\mathrm{Mn}$ was measured in order to determine the relative sensitivities for the elements. The mixed standard solution was prepared from commercial $1000 \mathrm{ppm}$ standard solution of $\mathrm{Ca}, \mathrm{V}, \mathrm{Cr}$, and $\mathrm{Mn}$. A $20-\mu \mathrm{L}$ portion of the mixed standard solution was pipetted onto the optical flat, and was then dried on a heating plate. The mixed standard solution sample contained $20 \mathrm{ng}$ of $\mathrm{Ca}, \mathrm{V}, \mathrm{Cr}$, and $\mathrm{Mn}$, respectively. Because the $1000 \mathrm{ppm} \mathrm{Cr}$ standard solution contained $\mathrm{K}_{2} \mathrm{Cr}_{2} \mathrm{O}_{7}, 0.75 \mathrm{ppm}$ of potassium was contained in the mixed standard solution. Fifteen nanograms of $\mathrm{K}$ were also contained in the mixed standard solution sample. The size of the dry residue was about $2 \mathrm{~mm}$ in diameter, and the dry residue was measured for $1000 \mathrm{~s}$. The relative sensitivities were determined by the following equation:

$$
S_{\mathrm{i}}=S_{\mathrm{rf}}\left(\frac{C_{\mathrm{rf}} I_{\mathrm{i}}}{C_{\mathrm{i}} I_{\mathrm{rf}}}\right),
$$

where $S_{\mathrm{i}}$ is the relative sensitivity for an elements, $S_{\mathrm{rf}}$ is the relative sensitivity for an internal standard element, $I_{\mathrm{i}}$ is the net intensity of fluorescent X-ray peaks of an element (counts/s), $C_{\mathrm{i}}$ is the concentration of an element (ppm), $I_{\mathrm{rf}}$ is the net intensity of fluorescent X-ray peaks of an internal standard element (counts/s), and $C_{\mathrm{rf}}$ is the concentration of an internal standard element $(\mathrm{ppm})$. In the present paper, $S_{\mathrm{rf}}$ was defineded as unity.

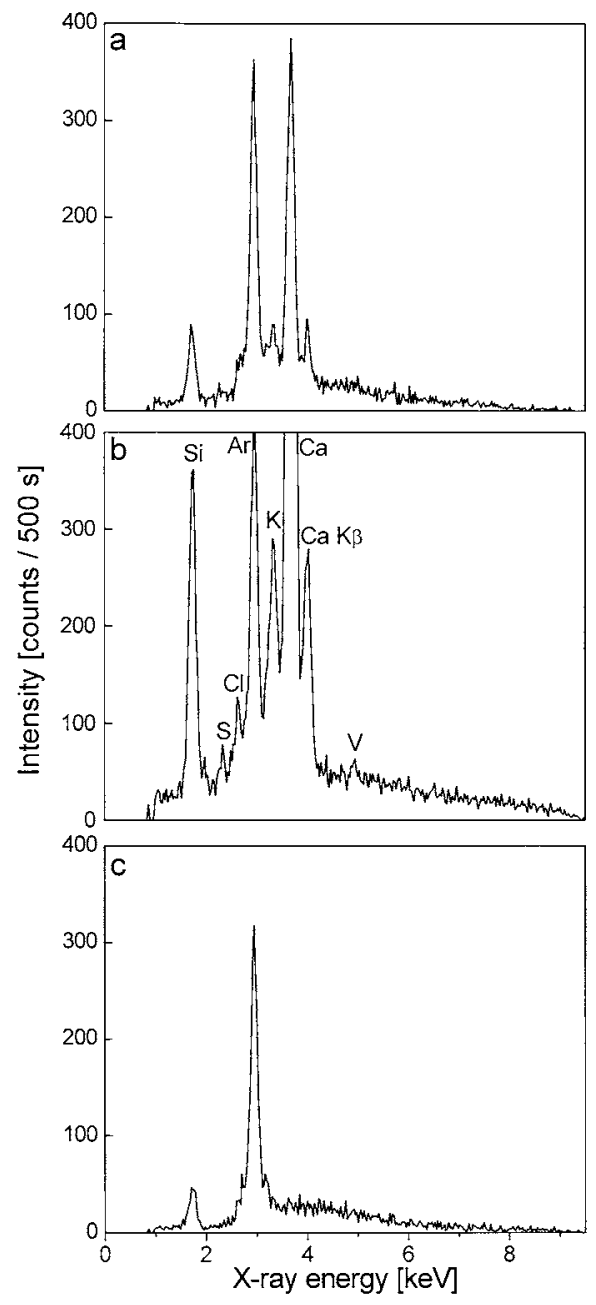

Fig. 1 Representative measured TXRF spectra of (a) a dry residue of drinking water of which size is about $17 \mathrm{~mm}$ in diameter, (b) a dry residue of the drinking water of which size is about $7 \mathrm{~mm}$ in diameter, and (c) the blank optical flat.

The drinking water and $10 \mathrm{ppm} \mathrm{Mn}$ standard solution were mixed in a 9:1 ratio. A $20-\mu \mathrm{L}$ portion of the drinking water containing $1 \mathrm{ppm}$ of $\mathrm{Mn}$ as an internal standard was pipetted onto the optical flat, and was then dried on a heating plate. The pipetting and drying were repeated six times. Three dry residues of drinking water containing $1 \mathrm{ppm}$ of $\mathrm{Mn}$ were prepared, and their sizes were about $7 \mathrm{~mm}, 7 \mathrm{~mm}$, and $10 \mathrm{~mm}$ in diameter, respectively. These three dry residues contained 140 ng of Mn, $8 \mathrm{ng}$ of V, $945 \mathrm{ng}$ of $\mathrm{Ca}$, and $126 \mathrm{ng}$ of K. These three dry residues were measured for $1000 \mathrm{~s}$, and each dry residue was measured twice at two sample positions such that a region of a dry residue directly below the detector was changed. The areas of the three dry residues were larger than the effective detection area of the detector $\left(7 \mathrm{~mm}^{2}\right)$, and the detection sensitivities for elements in a region of a dry residue that was directly below the detector was the highest. The concentrations of $\mathrm{V}, \mathrm{Ca}$, and $\mathrm{K}$ in the mixed solution which were quantified by using an internal standard were also determined by Eq. (1). The $S_{\mathrm{i}}$ and $S_{\mathrm{rf}}$ values used for quantifying the elements were obtained from a measurement of the mixed standard solution containing $1 \mathrm{ppm}$ of $\mathrm{Ca}, \mathrm{V}, \mathrm{Cr}$, and $\mathrm{Mn}$. The quantified concentrations of $\mathrm{V}, \mathrm{Ca}$, and $\mathrm{K}$ in the drinking water were $10 / 9$ times as high as those determined by Eq. (1), because the drinking water was diluted by the Mn standard solution. 


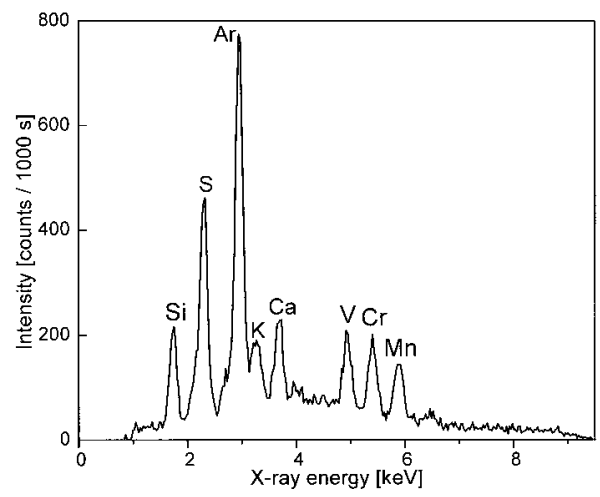

Fig. 2 Representative measured TXRF spectrum of a dry residue of mixed standard solution containing $1 \mathrm{ppm}$ of $\mathrm{Ca}, \mathrm{V}, \mathrm{Cr}$, and $\mathrm{Mn}$, and $0.75 \mathrm{ppm}$ of $\mathrm{K}$.

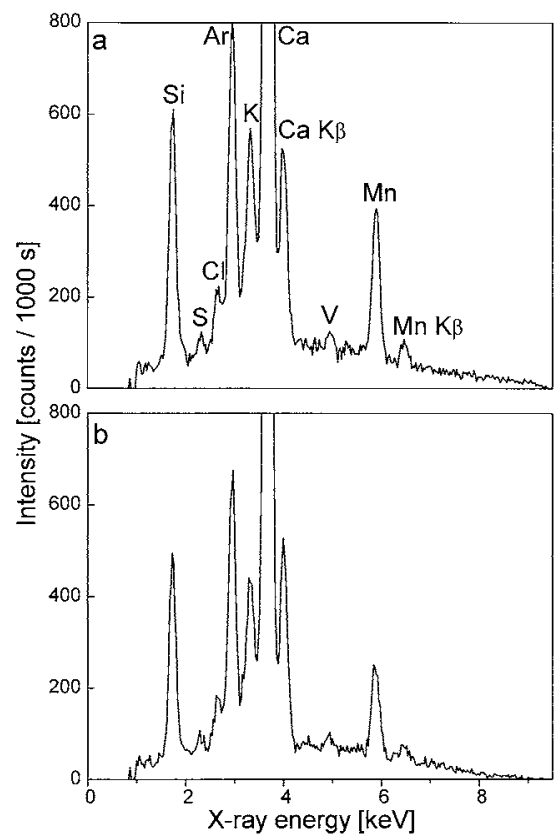

Fig. 3 Representative TXRF spectra of a dry residue of drinking water containing $1 \mathrm{ppm}$ of $\mathrm{Mn}$ as an internal standard element measured at different sample positions such that a region of the dry residue directly below the detector was changed.

\section{Results and Discussion}

Figure 1 shows representative measured TXRF spectra of $(a, b)$ dry residues of drinking water and (c) the blank optical flat. Calcium and potassium were detected as shown in Figs. 1(a) and (b). Vanadium was not detected in Fig. 1(a). The area of the dry residue, of which size was about $17 \mathrm{~mm}$ in diameter, was larger than the area where the surface of the optical flat was illuminated by the incident X-ray beams, and the incident X-ray beams did not fully illuminate this dry residue. The area of the dry residue, of which size was about $7 \mathrm{~mm}$ in diameter, was smaller than the area illuminated by the incident X-ray beams. Consequently, the sensitivity of this portable spectrometer was increased by reducing the size of the dry residue, and vanadium was detected in Fig. 1(b). Sulfur and chlorine were also detected in Fig. 1(b). Argon was detected in all spectra in Fig. 1
Table 1 Representative results of the quantification of drinking water

\begin{tabular}{lccc}
\hline & \multicolumn{3}{c}{ Concentration of an element, ppm } \\
\cline { 2 - 4 } & $\mathrm{V}$ & $\mathrm{Ca}$ & $\mathrm{K}$ \\
\hline Dry residue 1a & 0.044 & 7.7 & 1.3 \\
Dry residue 1b & 0.056 & 7.4 & 1.1 \\
Dry residue 2a & 0.100 & 14.2 & 2.2 \\
Dry residue 2b & 0.167 & 8.4 & 1.5 \\
Dry residue 3a & 0.111 & 6.3 & 1.3 \\
Dry residue 3b & 0.067 & 5.4 & 1.4 \\
Mean value & 0.091 & 8.2 & 1.5 \\
Standard deviation & 0.045 & 3.1 & 0.4 \\
\hline
\end{tabular}

Three dry residues of drinking water (dry residues 1,2 , and 3 ) were measured; each dry residue was measured twice at different sample positions such that a region of the dry residue directly below the detector was changed.

as well as Si because the air contained 0.93 vol\% $\mathrm{Ar}$ and the sample holder was $\mathrm{SiO}_{2}$. The silicon $K_{\alpha}$ peak intensity in Fig. 1(b) was higher than that in Fig. 1(c). This result indicated that $\mathrm{Si}$ was also contained in this dry residue of the drinking water. The silicon $K_{\alpha}$ peak intensity in Fig. 1(b) was higher than that in Fig. 1(a). The spectral background in Fig. 1(b) was higher than that in Fig. 1(c). The increase of the background intensity resulted from scattered X-rays from the dry residue. The spectral background in Fig. 1(b) was higher than that in Fig. 1(a). The background intensity increased with an increase of the sample thickness; this result indicated that the thickness of the dry residue of which size was about $7 \mathrm{~mm}$ in diameter was more than that of the dry residue of which size was about 17 $\mathrm{mm}$ in diameter.

Figure 2 shows a representative measured TXRF spectrum of a dry residue of mixed standard solution. As shown in Fig. 2, $\mathrm{K}, \mathrm{Ca}, \mathrm{V}, \mathrm{Cr}$, and $\mathrm{Mn}$ were detected. Sulfur was detected because the $1000 \mathrm{ppm} \mathrm{V}$ standard solution contained $0.45 \mathrm{~mol} / \mathrm{L}$ of $\mathrm{H}_{2} \mathrm{SO}_{4}$. The relative sensitivities for $\mathrm{K}, \mathrm{Ca}$, and $\mathrm{V}$ were 0.49 , 1.35 , and 1.16 , respectively.

Figure 3 shows representative TXRF spectra of a dry residue of the drinking water containing $1 \mathrm{ppm}$ of $\mathrm{Mn}$ as an internal standard element measured at different sample positions. As shown in Fig. 3, Mn, V, Ca, and $\mathrm{K}$ were detected, but the $\mathrm{K}$ and Mn $K_{\alpha}$ peak intensities in Fig. 3(a) were higher than those in Fig. 3(b). Table 1 gives representative results for the quantification of the drinking water. The average quantified concentrations of $\mathrm{V}, \mathrm{Ca}$, and $\mathrm{K}$ in the bottled drinking water were $91 \pm 45 \mathrm{ppb}$ (mean \pm standard deviation), $8.2 \pm 3.1 \mathrm{ppm}$, and $1.5 \pm 0.4 \mathrm{ppm}$, respectively. The three dry residues were inhomogeneous because of repeating the pipetting and drying; it was possible that the distributions of $\mathrm{K}, \mathrm{Ca}, \mathrm{V}$, and $\mathrm{Mn}$ were different. Consequently, the variability of quantified concentrations of these elements was happened as given in Table 1. However, it was possible for this portable spectrometer to estimate approximate concentrations.

\section{Conclusions}

A portable spectrometer with a $1.5 \mathrm{~W}$ X-ray tube was applied to commercial bottled drinking water containing $62 \mathrm{ppb}$ of vanadium. Although the continuum X-rays emitted from the low-power X-ray tube were used as the excitation source, ppb concentrations or nanograms of vanadium were detected. In the 
quantification of a sample, it was possible for this portable spectrometer to estimate the approximate concentrations of elements by a simple quantification. This kind of small and highly sensitive spectrometer is possible to be used for the rapid monitoring of elements in the field, or to be used for rapid sample screening before using large stationary elemental analyzers.

\section{Acknowledgements}

The present research was financially supported by the Asahi Glass Foundation.

\section{References}

1. R. Klockenkämper, "Total Reflection X-ray Fluorescence Analysis", 1997, Wiley, New York.

2. P. Wobrauschek, $X$-Ray Spectrom., in press.

3. Y. Yoneda and T. Horiuchi, Rev. Sci. Instrum., 1971, 42, 1069.

4. R. P. Stössel and A. Prange, Anal. Chem., 1985, 57, 2880.

5. D. J. Leland, D. B. Bilbrey, D. E. Leyden, P. Wobrauschek, H. Aiginger, and H. Puxbaum, Anal. Chem., 1987, 59, 1911.
6. A. Prange, H. Böddeker, and K. Kramer, Spectrochim. Acta, Part B, 1993, 48, 207.

7. A. von Bohlen, H. Brink-Kloke, and C. Althoff, Anal. Chim. Acta, 2003, 480, 327.

8. P. Freimann and D. Schmidt, Spectrochim. Acta, Part B, 1989, 44, 505.

9. M. Óvári, M. Mages, S. Woelfl, W. von Tümpling, K. Kröpfl, and Gy. Záray, Spectrochim. Acta, Part B, 2004, 59, 1173.

10. P. Wobrauschek, R. Görgl, P. Kregsamer, C. Streli, S. Pahlke, L. Fabry, M. Haller, A. Knöchel, and M. Radtke, Spectrochim. Acta, Part B, 1997, 52, 901.

11. U. Waldschläger, Adv. X-Ray Anal., 2000, 43, 418.

12. M. Mages, S. Woelfl, M. Óvári, and W. von Tümpling, Spectrochim. Acta, Part B, 2003, 58, 2129.

13. T. Yamada, M. Matsuo, N. Kawahara, Y. Shimizu, and M. Mantler, Abstracts of Papers, 12th Conference on Total Reflection X-Ray Fluorescence Analysis and Related Methods, Trento, Italy, 2007, Abstract, 44.

14. S. Kunimura and J. Kawai, Anal. Chem., 2007, 79, 2593.

15. S. Kunimura, J. Kawai, and K. Marumo, Adv. X-Ray Chem. Anal. Japan, 2007, 38, 367.

16. H. J. Sánchez, Nucl. Instrum. Methods Phys. Res., Sect. B, 2002, 194, 90.

17. R. E. Ayala Jiménez, Spectrochim. Acta, Part B, 2001, 56, 2331. 